\title{
Robust statistical modelling of hawksbill sea turtle growth rates (southern Great Barrier Reef)
}

\author{
M. Y. Chaloupka*, C. J. Limpus \\ Queensland Department of Environment, PO Box 155, Brisbane Albert Street, Queensland 4002, Australia
}

\begin{abstract}
Growth rates recorded between 1974 and 1991 for 44 immature hawksbill sea turtles in the southern Great Barrier Reef foraging grounds were modelled using nonparametric regression methods. The implicit sampling design in this long-term mark-recapture program was mixed longitudinal and included growth records for both female and male hawksbills ranging between 39 and $85 \mathrm{~cm}$ CCL (curved carapace length). Distinct sex-specific growth patterns were found, with immature female


mean-size specific growth rate function for females was nonmonotonic, rising rapidly from recruitment size (>35 cm CCL) to a maximum growth rate of $2.2 \mathrm{~cm} \mathrm{yr}^{-1}$ at $60 \mathrm{~cm}$ CCL before declining to negligible growth approaching sexual maturity at a size $\geq 80 \mathrm{~cm} \mathrm{CCL}$. The mean-size specific growth rate function for males was also nonmonotonic, rising from the same recruitment size to a maximum growth rate of $1.7 \mathrm{~cm} \mathrm{yr}^{-1}$ at $60 \mathrm{~cm} \mathrm{CCL}$ before declining to negligible growth approaching sexual maturity $\geq 80 \mathrm{~cm} \mathrm{CCL}$. No significant inter-annual variation in growth rates was found but the data set was too small to be conclusive. Size-specific growth rates were slower than observed for stocks from western Atlantic-Caribbean waters. Juvenile hawksbill growth spurts around $60 \mathrm{~cm} \mathrm{CCL}$, sex-specific growth and slow size-specific growth rates are distinct growth characteristics for immature hawksbill sea turtles resident in southern Great Barrier Reef waters.
\end{abstract}

KEY WORDS: Somatic growth · Nonparametric regression · Hawksbill turtles · Great Barrier Reef

\section{INTRODUCTION}

The hawksbill sea turtle Eretmochelys imbricata is an endangered and little-known marine turtle species with a broad circumtropical distribution (Witzell 1983). The hawksbill has been subject to a long history of extensive human exploitation for local egg harvests (Frazier 1980. Mortimer 1992) and for the commercial tortoiseshell trade (Frazier 1980). Hawksbill stocks are in serious decline in many regions (Hughes 1973, Carr \& Stancyk 1975, Groombridge \& Luxmoore 1989, Mortimer 1992, Bjorndal et al. 1993, Limpus 1993a) with the northwestern and northeastern Australian genetic stocks (Broderick et al. 1994) representing some of the few remaining stocks with seemingly viable breeding populations (Limpus 1992, Loop et al. 1995).

\footnotetext{
·E-mail:s019953@student.uq.edu.au
}

Australia shares its migratory hawksbill stocks with at least Indonesia and the Solomon Islands (Miller et al. in press), where there are widespread harvests for local consumption and trade (Groombridge \& Luxmoore 1989). In northeastern Australian waters, hawksbills have a low probability of being caught incidentally in prawn fishery trawls but have quite a high probability of drowning once caught (Poiner \& Harris 1996). The hawksbill is harvested for the local tortoiseshell market in neighbouring Papua New Guinea waters (Hirth \& Rohovit 1992) with low levels of subsistence harvesting occurring in northern Australia (Limpus 1993a). The hawksbill sea turtle is clearly under threat globally (Groombridge \& Luxmoore 1989) and increasingly in northern Australian waters so that improved knowledge of this species is needed to ensure the long-term viability of various regional stocks.

We present here a comprehensive statistical analysis of hawksbill growth rates obtained from a long-term 
mark-recapture program of hawksbill turtles resident in southern Great Barrier Reef (sGBR) foraging grounds (Limpus 1992). The hawksbills considered in this study comprised an indistinguishable mixture of genetic stocks, presumably including hawksbills from the northeastern Australian genetic stock (Broderick et al. 1994). The growth model presented here provides a basis for a better understanding of hawksbill growth dynamics in general, which is poorly known (Chaloupka \& Musick 1997), and for modelling of regional hawksbill population viability.

Post-natal sea turtle somatic growth comprises separate ontogenetic growth compartments: (1) an epipelagic post-hatchling feeding phase followed by (2) a benthic feeding phase. These distinct ontogenetic phases (except perhaps for leatherbacks and flatbacks) are likely to have different growth characteristics (Chaloupka \& Musick 1997). Therefore, this study considers only the benthic feeding phase for hawksbill sea turtles (>35 cm CCL, curved carapace length, to near onset of sexual maturity) resident in SGBR foraging grounds. Hawksbills $<35 \mathrm{~cm}$ CCL have rarely been recorded from sGBR foraging grounds so the growth functions presented are not applicable to the unknown epipelagic phase (ca 4 to $35 \mathrm{~cm} \mathrm{CCL}$ ).

\section{METHODS AND MATERIALS}

Data set (hawksbill growth rates). The data set comprised 68 mark-recapture records for 44 immature hawksbill turtles tagged with monel and/or titanium tags in the sGBR foraging grounds between 1974 and 1991 (Limpus 1992). The data set included growth records for both female and male hawksbills ranging between 39 and $85 \mathrm{~cm} \mathrm{CCL}$. The 44 individual turtles comprised 30 females and 14 males providing 44 and 24 growth records respectively with $28 \%$ of individuals recaptured 2 or more times. All hawksbills in this data set were immature although some were larger than the mean size at sexual maturity at rookeries within the northern Great Barrier Reef (see Limpus 1992). Further details of this long-term mark-recapture program can be found in Limpus (1992), while Chaloupka \& Musick (1997) provide an overview of the sampling and tagging protocols inherent in sea turtle mark-recapture programs.

Capture-recapture profiles recorded for each turtle included the following metrics: curved carapace length $(\mathrm{cm} \mathrm{CCL})$ at first capture and recaptures, sex and maturity determined from visual examination of gonads using laparoscopy (see Limpus 1992), year of first capture and time-at-large since first capture or previous recapture. Only turtles with recapture intervals $\geq 11$ mo were included. Recapture intervals ranged from 11 mo to $7 \mathrm{yr}$ with a median recapture interval of 2 yr. Absolute growth rates were derived from these capture-recapture profiles, the growth rate metric being a standard first-order differential form (dCCL/ $\mathrm{d} t$ ), not to be confused with a specific growth rate $(1 / \mathrm{CCL} \cdot \mathrm{dCCL} / \mathrm{dt})$. Both negative and zero growth rates were included in the analysis because, as noted by Chaloupka \& Limpus (1996), there is no statistically valid reason to do otherwise.

Sampling design. Demographic processes such as growth are complex time-dependent functions comprising 3 time effects (age, year, cohort). In other words there is natural variability in growth rates attributable to age-specific, inter-annual and cohort-specific factors (see Brillinger 1986). Year effect is considered an environmental factor while the cohort effect is considered a genetic factor Confounded time effects result in biased growth estimates (Tucker et al. 1995) so growth analyses need to uncouple the time effects by accounting for age, year and cohort factors (see Chaloupka \& Musick 1997). However, it is not always possible to uncouple the time effects in many studies because of limitations imposed by the mark-recapture sampling design and because of limitations in reliable aging of sea turtles (Chaloupka \& Musick 1997).

The implicit sampling design in this study was mixed longitudinal sampling (sampling with partial replacement) with $28 \%$ of individual hawksbills recaptured 2 or more times. Mixed longitudinal sampling enables the age, year and cohort effects to be uncoupled, but only if age is known. Because age was unknown, as in most sea turtle studies, the implicit sampling design in this study confounds year and cohort effects. A full discussion of time-dependent demographic sampling designs in relation to sea turtle studies is presented in Chaloupka \& Musick (1997).

Statistical modelling approach. The relationship between the absolute growth rates recorded for each hawksbill turtle and specific growth rate predictors or explanatory covariates was modelled statistically using a generalized additive modelling approach (see Hastie \& Tibshirani 1990).

A generalized additive model (GAM) is a nonparametric regression model that allows (1) flexıble specification of the error and link functions and (2) arbitrary specification of the functional form for each predictor included in the regression model. The GAM approach is a major extension of the familar general linear model (GLM; Draper \& Smith 1981, Cohen \& Cohen 1983) and the recent generalized linear model (glm; McCullagh \& Nelder 1989).

The GLM (parametric regression models such as linear regression, ANOVA, MANOVA) has many limiting assumptions including (1) normal error, (2) identity link of the response variable and (3) linear func- 
tional form for each covariate included in the model. Linear form includes polynomial functional form. On the other hand, the glm approach supports more flexible link specification and relaxes the normality assumptions, but the constraint of linear predictor form still remains.

The GAM approach relaxes the normality assumptions and supports flexible link specification while the functional form (linear, nonlinear) for each predictor is estimated from the data using a scatterplot smoother conditioned on all other covariates included in the regression model. A GAM therefore remains additive (unlike nonlinear regression) and hence simple to interpret by comprising a separate function for each predictor in the regression model similar to the GLM and $\mathrm{glm}$ approaches. Examples of GAM models used in a variety of settings can be found in Hastie \& Tibshirani (1987; ANCOVA-type field experiments, risks factors in heart disease), Swartzman et al. (1992; spatial analysis of fish stock distributions) and Chaloupka et al. (1994; epidemiology of ciguatera poisoning).

The GAM is complementary with modern statistical visualisation techniques (Cleveland 1993) that allow exploratory analysis of complex data sets including evaluation of the major assumptions of the GLM (normality, identity link, linear functional form). Preliminary analysis of the hawksbill growth data set based on data visualisation revealed that neither a GLM nor a glm approach to modelling the sGBR hawksbill growth would be worthwhile - in fact, as discussed below, a GLM would have resulted in erroneous conclusions about hawksbill growth.

The specific GAM regression model presented here used an identity link, a robust quasi-likelihood error function (Hastie \& Tibshirani 1990) and reasonably stiff cubic smoothing splines to minimise small sample size and outlier effects on estimating nonlinear covariate form and regression parameter estimates. The robust estimator incorporated in the quasi-likelihood error function minimises the influence of outliers on parameter estimation (Hastie \& Tibshirani 1990). Robust esti- mators are important because sea turtles display considerable individual growth variability. A quasilikelihood error function is quite general and precludes a need to assume a specific parametric error distribution (unlike the GLM) depending only on a mean-variance relationship derived from the data (McCullagh \& Nelder 1989). The parameter estimates are therefore quasi-likelihood estimates modelled simultaneously with estimation of the mean-variance dispersion parameter. The dispersion parameter is used in computation of standard error and $t$-ratio values for each parameter and has a profound influence on statistical inference. The quasi-likelihood error function is also a means of accounting for potential correlated error due to the mixed longitudinal nature of the data (McCullagh \& Nelder 1989).

The GAM fit and inference summary used here comprises 2 parts: (1) an estimate of the contribution of each predictor to the overall model fit using $t$-ratio statistical inference similar to the GLM and (2) an estimate of the nonlinearity for each continuous predictor using a Rao-type score or nonparametric F-ratio test statistic (Hastie \& Tibshirani 1990). Both summary components were arranged into a single tabular format for ease of reporting and interpretation.

\section{RESULTS}

The GAM model comprised 1 response variable (absolute growth rates) and 4 potential growth factors (sex, mean.size, year, recapture.interval; see Table 1 , Fig. 1). The sex factor is self evident ( $1=$ female, $2=$ male; Fig. 1a). Mean.size is the arithmetic mean of CCL at first capture and CCL at subsequent recapture. Mean.size is the appropriate size metric for indexing size-specific growth (see Fig. 1b) assuming that growth is locally linear or constant within the sampling interval (see Ricker 1979). This assumption is reasonable so long as relatively short sampling intervals are used. However, in long-term mark-recapture programs sam-

Table 1. Summary of parameter estimates for GAM model with robust quasi-likelihood error term and cubic smoothing splines (nominal $\mathrm{d} f=3$ ) fitted to hawksbill turtle growth rates. Null deviance $=44.31$, null $\mathrm{df}=67$, residual deviance $=17.69$, residual $\mathrm{df}=$ 54.1, quasi-likelihood dispersion parameter $=0.2812, R^{2}=(44.31-17.69) / 44.31=0.601$. npar: non-parametric (nonlinear) effects; $\mathrm{df}$ : degrees of freedom; ns: not significant; $\operatorname{Prob}(F)$ based on npar df and residual df

\begin{tabular}{|c|c|c|c|c|c|c|c|}
\hline \multirow[t]{2}{*}{ Parameter } & \multirow[t]{2}{*}{ Estimate } & \multirow{2}{*}{$\begin{array}{l}\text { Asymptotic } \\
\text { standard error }\end{array}$} & \multirow[t]{2}{*}{$t$-ratio } & \multirow[t]{2}{*}{$\operatorname{Prob}(t)$} & \multicolumn{3}{|c|}{ Nonlinear effects (nonparametric) } \\
\hline & & & & & npar df & npar $F$ & $\operatorname{Prob}(F)$ \\
\hline (constant) & 4.1826 & 2.0675 & 2.0230 & $\mathrm{p}<0.05$ & & & \\
\hline $\operatorname{sex}$ & -0.4759 & 0.1413 & -3.3689 & $\mathrm{p}<0.001$ & & & \\
\hline mean.size & -0.0130 & 0.0055 & -2.3672 & $p<0.05$ & 3 & 13.238 & $\mathrm{p}<0.0001$ \\
\hline year & -0.0205 & 0.0239 & -0.8568 & ns & 3 & 1.177 & ns \\
\hline recapture interval & 0.0001 & 0.0001 & 0.9790 & ns & 3 & 1.657 & ns \\
\hline
\end{tabular}



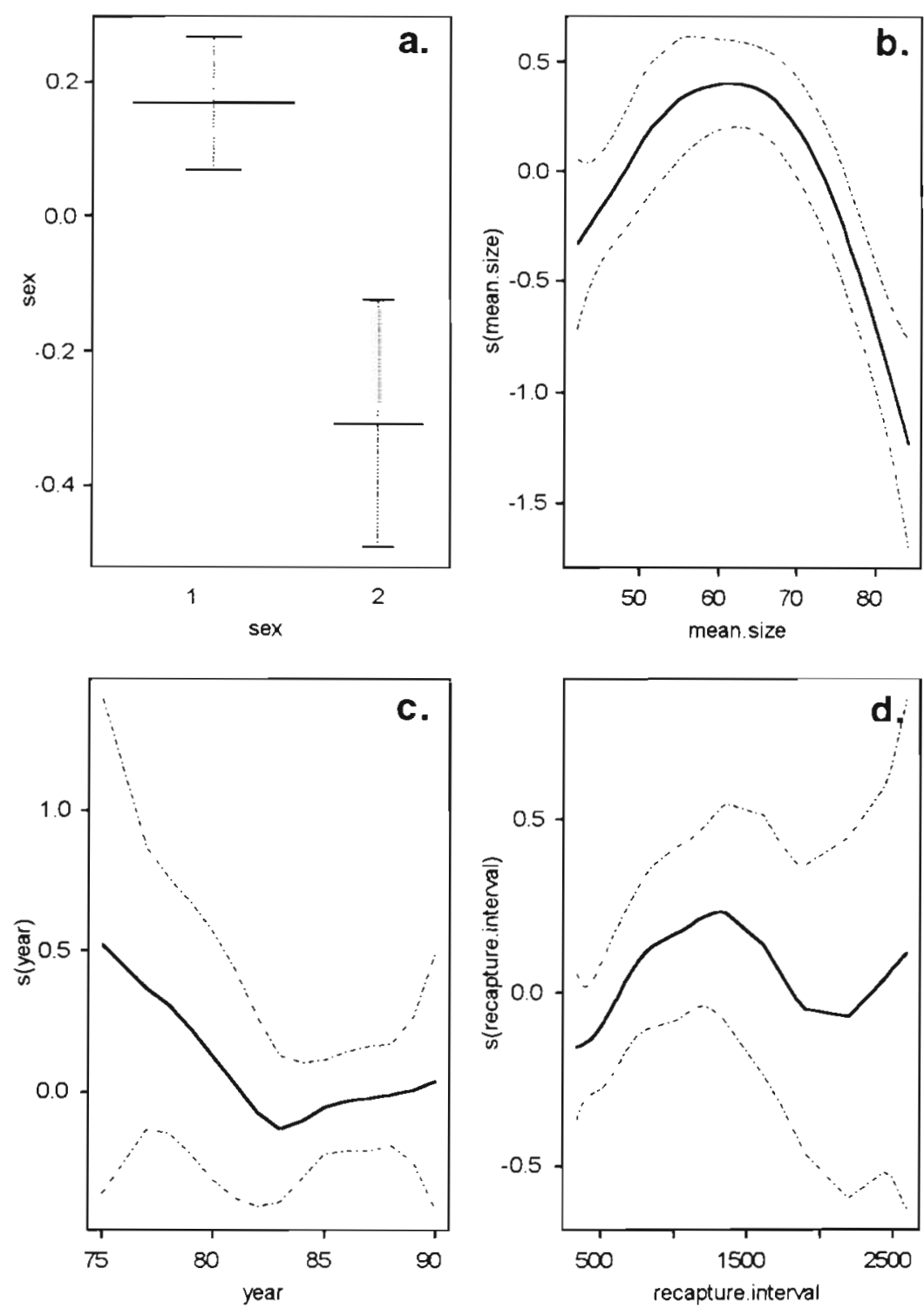

Fig. 1. Graphical summary of GAM model fit summarised in Table 1. Response variable (growth rate) shown on $y$-axis as a centred smoothed function scale to ensure valid pointwise $95 \%$ confidence bands. Covarlate shown on the $x$-axis (a) $\operatorname{sex}(1=$ females, 2 = males), (b) year (year of growth record), (c) mean.size [mean CCL $(\mathrm{cm})$ between first capture and next recapture] and (d) recapture.interval in years. The width of the mean factor response $\left(a_{;}\right.$sex $)$is proportional to sample size with the $95 \%$ confidence interval shown by cross bars Solid curves in (b) to (d) are the cubic smoothing spline fits for each continuous covariate conditioned on all other covariates in the GAM model (see Table 1). Dotted curves in (b) to (d) are pointwise $95 \%$ confidence curves around the fits

pling intervals usually span a considerable time range. For instance, in the current study sampling intervals (recapture interval) ranged from 11 mo to $7 \mathrm{yr}$ (median $=2 \mathrm{yr}$ ) so that this factor has been included in the model to account for potential bias due to variable sampling interval.

Year is the calendar year of the growth record and was included to account for the implicit time-depen- dent sampling design (Fig. 1c). The year effect is a potential source of growth variability due to environmental factors but because of the implicit mixed longitudinal sampling design it was confounded with unknown cohort effects. If age for each turtle had been known (rarely the case for sea turtle studies), then it would have been possible to decouple the confounded year and cohort effects (see Chaloupka \& Musick 1997). Whatever the year effect really measures in any particular study, it should always be included in a model because it is a time series sampling design constraint inherent in all mark-recapture programs - it is simply an unavoidable part of any growth study.

The GAM regression analysis suggested that irnmature hawksbill growth rates were dependent on both sex and mean.size effects (Table 1, Fig.1a, b). Size-specific growth rates are referenced to mean size between recaptures rather than initial size at capture. Mean.size is considered a more reliable approximation of a complex and instantaneous growth process (see Ricker 1979). Female growth rates were significantly different from male growth rates, with immature females growing on average about $0.5 \mathrm{~cm} \mathrm{yr}^{-1}$ faster than immature males (Table 1, Fig. 1a). Size was not only a significant covariate affecting growth rates but was also a significant nonlinear covariate (Table 1, Fig. 1b). On the other hand, hawksbill growth rates were independent of either year (Table 1, Fig. 1c) or recapture.interval effects (Table 1, Fig. 1d). Neither year nor recapture.interval effects displayed any nonlinearity (Table 1).

The GAM nonparametric regression model was a good fit to the growth data as shown by a small residual deviance relative to residual degrees of freedom (Table 1), acceptable nonparametric $R^{2}$ (Table 1) and no aberrant residual behaviour. The robust quasi-likelihood dispersion parameter (Table 1) suggests that an arbitrary error function was more appropriate than a normal or Gaussian error function (see McCullagh \& Nelder 1989). However, the $R^{2}=0.601$ (Table 1) indicated that 
while the GAM regression model accounted for at least $60 \%$ of the growth variance, immature hawksbills still displayed significant individual growth variation.

Covariate function plots for a GAM model fit (see Fig. 1) are centred on the response scale by subtracting a weighted mean to ensure valid pointwise $95 \%$ confidence bands (see Hastie \& Tibshirani 1990). While essential for analytical purposes, centred plots are more difficult for the user to decode on the original response (i.e. growth rate) scale. To aid interpretation of the size-specific growth functions the predicted GAM model values were re-plotted on the uncentred growth rate scale for each sex with a cubic B-spline smooth superimposed to highlight the underlying nonlinear function (Fig. 2). Pointwise confidence bands are no longer valid in this format but the fitted model values provide a clear indication of the growth variability around the smoothed sex-specific growth functions in Fig. 2.

Distinct sex-specific growth patterns are clearly evident in Fig. 2, with immature female hawksbills growing about $0.5 \mathrm{~cm} \mathrm{yr}^{-1}$ faster than male immature hawksbills at all recorded sizes (compare Fig. 2a and $2 \mathrm{~b}$, see also Table 1). The fitted expected size-specific growth rate function for females was nonmonotonic, rising rapidly from the benthic phase recruitment size (>35 cm CCL) to a maximum growth rate of $2.2 \mathrm{~cm} \mathrm{yr}^{-1}$ at about $60 \mathrm{~cm}$ CCL before declining to negligible growth approaching sexual maturity at a size $\geq 80 \mathrm{~cm}$ $\mathrm{CCL}$. The fitted expected size-specific growth rate function for males was also nonmonotonic rising from the same recruitment size to maximum growth of $1.7 \mathrm{~cm} \mathrm{yr}^{-1}$ at about $60 \mathrm{~cm} \mathrm{CCL}$ before declining to negligible growth approaching sexual maturity at $\geq 80 \mathrm{~cm}$ CCL. The growth rate functions (Fig. 2) are monophasic (see Chaloupka \& Musick 1997) displaying a single growth cycle with a growth peak or growth spurt for either sex at around $60 \mathrm{~cm} \mathrm{CCL}$.

The advantage of using a GAM model rather than a GLM model is quite apparent when the results of both approaches are compared. For instance, a linear regression model including a quadratic polynomial mean size function accounted for only $31 \%$ of the variance compared to the GAM fit of $60 \%$ shown in Table 1. Yet the GLM model did not find the significant sex effect that was clearly evident in the data using data visualisation techniques (see Cleveland 1993) and supported by the GAM model analysis. Moreover, the
GLM model suggested that there was a significant year effect, an effect that was discounted by the GAM fit when the correct nonlinear functional form for the other covariates was used.

Whichever way you look at it, the GAM model is a good fit while the GLM model (with or without polynomial functional form) is a poor fit to these hawksbill growth data. It would seem that statistical modelling of sea turtle growth data might be more effective using nonparametric regression models that incorporate both nonlinear functional form and non-normal error structures. However, it is important to understand that since the sampling design was mixed longitudinal with unknown age, the growth model cannot account adequately for potential bias due to confounded year and cohort effects. How serious this potential bias would be is unknown but is an important issue rarely considered in biological growth modelling in general (see Chaloupka \& Musick 1997).

\section{DISCUSSION}

Somatic growth of wild stock hawksbill sea turtles is poorly known (Chaloupka \& Musick 1997). There are several compilations of growth rates of hawksbills reared in captivity (Witzell 1983, Zug et al. 1986. Godinez-Dominguez et al. 1993), but these data bear little resemblance to growth observed in wild stocks. For instance, hawksbill growth in captivity is much faster than growth in wild stocks (Limpus 1992). More- 
over, captivity studies involve longitudinal sampling with known age, resulting in confounded age and year effects (Chaloupka \& Musick 1997). On the other hand, wild stock growth studies invariably involve mixed longitudinal sampling with unknown age, confounding cohort and year effects. The 2 sampling designs lead to different sampling biases for time-dependent demographic processes such as growth (see discussion in Chaloupka \& Musick 1997).

The hawksbills considered in this study were from an indistinguishable mixture of genetic stocks resident in southern Great Barrier Reef waters. Australia shares its migratory hawksbill stocks with at least Indonesia to the north and the Solomon Islands in the west (Miller et al. in press). The hawksbills were all immature, ranging from 39 to $85 \mathrm{~cm} \mathrm{CCL}$ in size with both sex and maturity status confirmed using laparoscopy (Limpus 1992). Hawksbills $\leq 35 \mathrm{~cm}$ CCL have rarely been recorded from $\mathrm{sGBR}$ habitats so the growth functions presented here are not applicable for extrapolation to the poorly known epipelagic phase (ca 4 to $35 \mathrm{~cm}$ CCL). Moreover, mature adults were not included in this study because they have been poorly represented in samples from sGBR waters. The lack of adult hawkbills has been inferred to indicate a developmental migration to northern Australian waters (Limpus 1992). Hawksbill nesting for this stock occurs in the northern Great Barrier Reef, the Torres Strait, Solomon Islands and in Papua New Guinea waters (Limpus 1980, Limpus et al. 1983, Miller et al. in press).

The most comprehensive previous analysis of growth in wild hawksbills was presented by Limpus (1992) using data collected during the earlier years of the current study. Limpus (1992) used a growth interval method (see Chaloupka \& Musick 1997) and concluded that immature hawksbill growth was nonmonotonic, peaking at 50 to $60 \mathrm{~cm} \mathrm{CCL}$ then declining to very slow growth by 80 to $90 \mathrm{~cm}$ CCL. Limpus (1992) identified no sex-specific growth differences and presented no analytical growth functions.

The statistical growth rate modelling in the current study confirmed the nonmonotonic growth pattern suggested by Limpus (1992) but also found a significant difference in sex-specific growth rates (Table 1. Fig. 2). The distinct monophasic growth pattern with a growth spurt for both female and male immature hawksbills at around $60 \mathrm{~cm}$ CCL (see Fig 2) or at any other size for that matter has not been recorded for any other hawksbill stock. On the other hand, Bjorndal \& Bolten (1988) and Boulon (1994) have proposed a monotonic decreasing size-specific growth rate function for immature hawksbills resident in western Atlantic-Caribbean waters. A monotonic decreasing growth function suggests no growth spurt behaviour and infers a von Bertalanffy size-at-age growth func- tion (see Chaloupka \& Musick 1997). However, both studies were based on limited data sets and questionable sampling designs (see Chaloupka \& Musick 1997).

Nonetheless, the apparent distinct regional growth patterns (monotonic vs nonmonotonic size-specific growth functions) might be real and due to distinct regional growth rate characteristics. Size-specific growth rates for the northeastern Australian genetic stock are much slower than stocks from western Atlantic-Caribbean waters where growth spurts are not evident (Bjorndal \& Bolten 1988, Boulon 1994). For instance, Boulon (1994) found a mean growth rate for immature hawksbills in U.S. Virgin Island waters of $3.5 \mathrm{~cm}$ straight carapace length $(\mathrm{SCL}) \mathrm{yr}^{-1}$ (SE $=0.52$ ). Unfortunately, the hawksbill growth data in Bjorndal \& Bolten (1988) are too limited for comparative purposes. For the current study in the sGBR region, the mean growth rate for immature females was $1.8 \mathrm{~cm} \mathrm{CCL} \mathrm{yr}^{-1}$

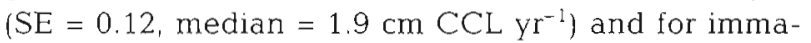
ture males it was $1.2 \mathrm{~cm} \mathrm{CCL} \mathrm{yr}^{-1}(\mathrm{SE}=0.15$, median $=$ $1.3 \mathrm{~cm} \mathrm{CCL} \mathrm{yr}^{-1}$ ). Even allowing for the transformation of $\mathrm{SCL}$ to $\mathrm{CCL}$ growth values, it would seem that immature hawksbills grow much faster in the western Atlantic-Caribbean region than in the sGBR region.

Inter-regional differences in immature growth rates could also explain why mature female hawksbills in northern Australian waters are apparently smaller than hawksbills nesting in the Caribbean and in the Seychelles (van Buskirk \& Crowder 1994). The mean nesting female hawksbill size in northern Australia is about $83 \mathrm{~cm} \mathrm{CCL}$ (range 76 to $93 \mathrm{~cm} \mathrm{CCL)} \mathrm{or} 76 \mathrm{~cm}$ SCL (Limpus et al. 1983, see also Loop et al. 1995). However, most hawksbill data sets are still too small for comparative growth analysis purposes. On the other hand, adult hawksbill growth is consistently recorded across regions as either negligible or perhaps having ceased altogether. For instance, Bjorndal et al. (1985) found that female hawksbills nesting at Tortuguero (Costa Rica) grew at about $0.3 \mathrm{~cm} \mathrm{yr}^{-1}$ at a mean size of $83 \mathrm{~cm} \mathrm{SCL}$. Limpus (1992) found mature adult growth rates of $0.06 \mathrm{~cm} \mathrm{yr}^{-1}$ at 80 to $90 \mathrm{~cm} \mathrm{CCL}$ for hawkbills from the sGBR.

The size-specific growth functions developed here for immature hawksbills resident in sGBR waters are the first substantial growth functions presented for a wild hawksbill stock. Except for this data set, which is itself an extension of the data set in Limpus (1992), there are no other sex-specific growth data sets available for hawksbill sea turtles. The female and male immature hawksbill size-specific growth functions are significantly different, with immature females growing much faster at all sizes than immature males (Table 1 , Fig. 2) implying sex-specific differences in size or age at maturity (i.e. adult size dimorphism). Nietschmann 
(1981) has proposed adult size dimorphism for a mixed stock of hawksbills in Nicaraguan waters but Limpus (1993b) has questioned those data. The sex-specific growth functions presented here (Fig. 2) indicate that mature adult male hawskbills from the sGBR are most likely to be smaller on average than mature adult female hawksbills. For the moment, there are no valid data on mean mature male size for hawksbills resident in Australian waters although Limpus et al. (1983) recorded 1 mature male from the northern Great Barrier Reef at $82 \mathrm{~cm} \mathrm{CCL}$.

The size-specific growth functions for the sGBR hawksbills (Fig. 2) could be numerically integrated to yield size-at-age growth functions useful for estimating age-specific growth functions and age at sexual maturity for either sex (see Chaloupka \& Limpus 1996). However, this hawksbill data set is currently too small and incomplete without mature adult records to warrant such further analysis. Nonetheless, it is clear from the size-specific growth functions (Fig. 2) that the onset of sexually maturity at a size $\geq 80 \mathrm{~cm} \mathrm{CCL}$ for either sex will take decades, as proposed by Limpus (1992).

Acknowledgements. We thank K. Bjorndal, R. Boulon, J Miller and the anonymous referees for helpful comments on the manuscript.

\section{LITERATURE CITED}

Bjorndal KA, Bolten AB (1988) Growth rates of immature green turtles Chelonia mydas on feeding grounds in the southern Bahamas. Copeia 1988:555-564

Bjorndal KA, Bolten AB, Lagueux CJ (1993) Decline of the nesting population of hawksbill turtles at Tortuguero, Costa Rica. Conserv Biol 7:925-927

Bjorndal KA, Carr A, Meylan AB, Mortimer JA (1985) Reproductive biology of the hawksbill Eretmochelys imbricata at Tortuguero Costa Rica with notes on the ecology of the species in the Caribbean. Biol Conserv 34:353-368

Boulon RH (1994) Growth rates of wild juvenile hawksbill turtles Eretmochelys imbricata in St Thomas United States Virgin Islands. Copeia 1994:811-814

Brillinger DR (1986) The natural variability of vital rates and assoclated statistics. Biometrics 42:693-734

Broderıck D, Moritz C, Miller JD, Guinea M, Prince RIT, Lımpus CJ (1994) Genetic studies of the hawksbill turtle Eretmochelys imbricata: evidence for multiple stocks in Australian waters. Pac Conserv Biol 1:123-131

Carr A, Stancyk S (1975) Observations on the ecology and survival outlook of the hawksbill turtle. Biol Conserv 8 : $161-172$

Chaloupka MY, Lewis RJ, Sellin M (1994) The changing face of ciguatera prevalence. Mem Queensland Mus 34:554

Chaloupka MY، Limpus CJ (1996) Robust statistical modelling of Chelonia mydas growth rates - southern Great Barrier Reef. In: Keinath JA, Barnard DE, Musick JA, Bell BA. (eds) Proceedings of the Fifteenth Annual Symposium on Sea Turtle Biology and Conservation, NOAA Tech Memo NMFS-SEFSC-387:62-65

Chaloupka MY, Musick JA (1997) Age, growth and population dynamics. In: Lutz PL, Musick JA (eds) The biology of sea turtles, Chap 9. CRC Marine Science Series. CRC Press Inc, Boca Raton, p 235-278

Cleveland WS (1993) Visualizing data. Hobart Press, Summit, NJ

Cohen J, Cohen P (1983) Applied multiple regression/correlation analysis for the behavioral sciences, 2nd edn. Lawrence Erlbaum, New York

Draper NR, Smith H (1981) Applied regression analysis, 2nd edn. John Wiley and Sons, New York

Frazier J (1980) Exploitation of manne turtles in the Indian Ocean. Hum Ecol 8:329-370

Godinez-Dominguez E, Carretero-Montes RE, Silva-Batiz F, Ruiz S, Aguilar B (1993) Crecimiento de neonatos de CheIonia agassizii (Testudines: (helonıdae) en cautiverio. Rev Biol Trop 41:253-260

Groombridge B, Luxmoore R (1989) The green turtle and hawksbill (Reptlla: Chelonildae): world status exploitation and trade. Convention on the International Trade in Endangered Species of Wild Fauna and Flora. International Union for the Conservation of Nature, Lausanne

Hastie TJ, Tibshirani RJ (1987) Generalized additive models: some applications. J Amer Statist Assoc 82:371-386

Hastie TJ, Tibshirani RJ (1990) Generalized additive models. Monographs on statistics and applied probability, 43. Chapman and Hall, London

Hirth HF, Rohovit DL (1992) Marketing patterns of green and hawksbill turtles in Port Moresby. Papua New Guinea. Oryx 26:39-42

Hughes GR (1973) The survival situation of the hawksbill seaturtle (Eretmochelys imbricata) in Madagascar Biol Conserv 5:114-118

Limpus CJ (1980) Observations on the hawksbill turtle (Eretmochelys imbricata) nesting along the Great Barrier Reef. Herpetologica 36:265-271

Limpus CJ (1992) The hawksbill turtle Eretmochelys imbricata in Queensland: population structure within a southern Great Barrier Reef feeding ground. Wildife Res 19: 489-506

Limpus CJ (1993a) The worldwide status of marine turtle conservation. In: Nacu A, Trono R, Palma JA, Torres D, Agas $F$ (eds) Proceedings of the First ASEAN SymposiumWorkshop on Marine Turtle Conservation. Manila, Philippines. World Wildlife Fund, Manila, p 43-61

Limpus CJ (1993b) The green turtle Chelonia mydas in Queensland: breeding males in the southern Great Barrier Reef. Wildlufe Res 20:513-523

Limpus CJ, Miller JD. Baker V, McLachlan E (1983) The hawksbill turtle Eretmochelys imbricata (L.) in northeastern Australia: the Campbell Island rookery. Aust Wildlife Res 10:185-197

Loop KA, Miller JD, Limpus CJ (1995) Nestıng by the hawksbill turtle (Eretmochelys imbricata) on Milman Island Great Barrier Reef. Aust Wildlife Res 22:241-252

McCullagh P. Nelder JA (1989) Generalized linear models, 2nd edn. Monographs on statıstics and applied probability, 37. Chapman and Hall, London

Miller JD, Loop KA, Mattocks N, Limpus CJ, Landry AM (in press) Long distance migration in the hawksbill turtle Eretmochelys imbricata from eastern Australia. Wildlife Res

Mortimer JA (1992) Marine turtle conservation in Malaysia. Malay Nat J 45:353-361

Nietschmann B (1981) Following the underwater trail of a vanishing species - the hawksbill turtle. Nat Geogr Soc Res Rep 13:459-480

Poiner IR, Harris ANM (1996) The incidental capture, direct mortality and delayed mortality of turtles in Australia's northern prawn fishery. Mar Biol 125:813-825 
Ricker WE (1979) Growth rates and models. In: Hoar WS, Randall DJ, Brett JR (eds) Fish physiology, Vol 8, Bioenergetics and growth, Chap 11. Academic Press, New York, p 677-743

Swartzman G. Huang C. Kaluzny S (1992) Spatial analysis of Bering Sea groundfish survey data using generalized additive models. Can J Fish Aquat Sci 49:1366-1378

Tucker JK, Maher RJ, Theiling CH (1995) Year-to-year variation in growth in the red-eared turtle Trachemys scripta elegans. Herpetologica 51:354-358

This article was submitted to the editor van Buskirk J, Crowder LB (1994) Life-history variation in marine turtles. Copeia 1994:66-81

Witzell WN (1983) Synopsis of biological data on the hawksbill turtles Eretmochelys imbricata (Linnaeus 1766). FAO Fish Syn 137:1-78

Zug GR, Wynn AH, Ruckdeschel C (1986) Age determination of loggerhead sea turtles Caretta caretta by incremental growth marks in the skeleton. Smithsonian Contrib Zool $427: 1-34$

Manuscript first received: June 27, 1996

Revised version accepted: December 3, 1996 